\title{
Influence of the Atmospheric Mass on the High Energy Cosmic Ray Muons during a Solar Cycle
}

\author{
A. H. Maghrabi, ${ }^{1}$ R. N. Alotaibi, ${ }^{2}$ M. M. Almutayri, ${ }^{1}$ and M. S. Garawi ${ }^{2}$ \\ ${ }^{1}$ National Centre for Applied Physics, King Abdulaziz City for Science and Technology, Riyadh 11442, Saudi Arabia \\ ${ }^{2}$ Physics and Astronomy Department, King Saud University, P.O. Box 2454, Riyadh 11451, Saudi Arabia \\ Correspondence should be addressed to A. H. Maghrabi; amaghrabi@kacst.edu.sa
}

Received 22 February 2015; Accepted 10 May 2015

Academic Editor: William Reach

Copyright (c) 2015 A. H. Maghrabi et al. This is an open access article distributed under the Creative Commons Attribution License, which permits unrestricted use, distribution, and reproduction in any medium, provided the original work is properly cited.

\begin{abstract}
The rate of the detected cosmic ray muons depends on the atmospheric mass, height of pion production level, and temperature. Corrections for the changes in these parameters are importance to know the properties of the primary cosmic rays. In this paper, the effect of atmospheric mass, represented here by the atmospheric pressure, on the cosmic ray was studied using data from the KACST muon detector during the 2002-2012 period. The analysis was conducted by calculating the barometric coefficient $(\alpha)$ using regression analysis between the two parameters. The variation of $\alpha$ over different time scales was investigated. The results revealed a seasonal cycle of $\alpha$ with a maximum in September and a minimum in March. Data from Adelaide muon detector were used, and different monthly variation was found. The barometric coefficient displays considerable variability at the interannual scale. Study of the annual variations of $\alpha$ indicated cyclic variation with maximums between 2008 and 2009 and minimums between 2002 and 2003. This variable tendency is found to be anticorrelated with the solar activity, represented by the sunspot number. This finding was compared with the annual trend of $\alpha$ for the Adelaide muon detector for the same period of time, and a similar trend was found.
\end{abstract}

\section{Introduction}

The rate of the detected cosmic ray muons depends on a number of meteorological factors, mainly the barometric effect, height of pion production level, and the temperature effect [1-4]. Correction for local variation in these factors has to be performed to determine the properties of the primary cosmic rays $[5,6]$. While the temperature effect is generally determined by the overall profile of the atmosphere from the level of origin to the detection level, the barometric effect is determined only by the pressure at sea level. The rate of the detected cosmic ray depends on the amount of material traversed above the detector, and the barometric pressure is taken as a measure of this mass [7-11].

It is very important to derive a certain appropriate barometer coefficient $(\alpha)$ to make a reliable correction of the counting rate for the atmospheric pressure.

Several studies have revealed that the value of the barometric coefficient $(\alpha)$ depends on a number of factors, such as the nature of the secondary component being detected and the geomagnetic latitude of the location [12-16].
In this paper, cosmic ray data from the KACST muon detector over a period of eleven years were used to derive and study the distribution in the barometer coefficient $(\alpha)$ over different time scales.

\section{Instrumentation and Methods}

Cosmic ray measurements were obtained from a KACST muon detector installed at Riyadh (lat. 24 43; long. 46 40; alt. $613 \mathrm{~m} ; \mathrm{Rc}=13 \mathrm{GeV}$ ) Saudi Arabia for the period between 2002 and 2012. The detailed descriptions for this detector and calibration procedures are given in [17-20].

The detector consists of $1000 \mathrm{~mm} \times 1000 \mathrm{~mm} \times 50 \mathrm{~mm}$ of plastic scintillator viewed by a photomultiplier tube (PMT). The outputs from the photomultiplier are amplified and digitized by analogue to digital converter, which is linked to a PC card. Atmospheric pressure and lab temperatures were instantaneously measured by locally designed sensors.

Due to the difficulty of maintaining yearlong measurements, there have been some downtimes in the operation of the detector causing data loss for some times during 


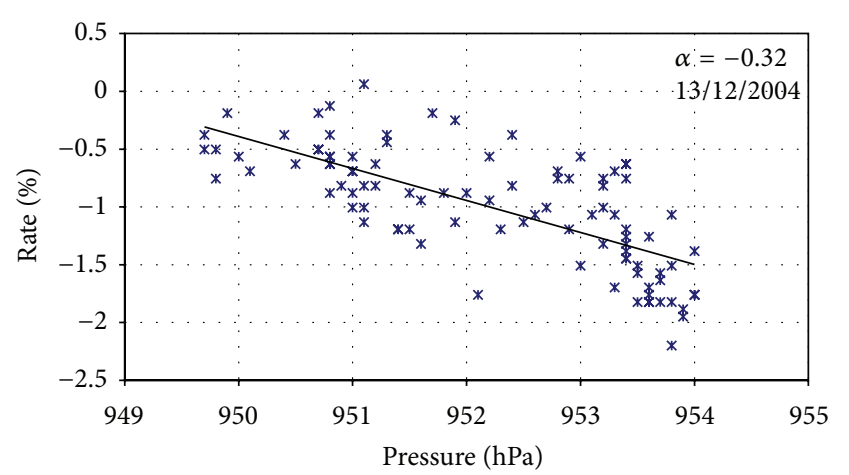

(a)

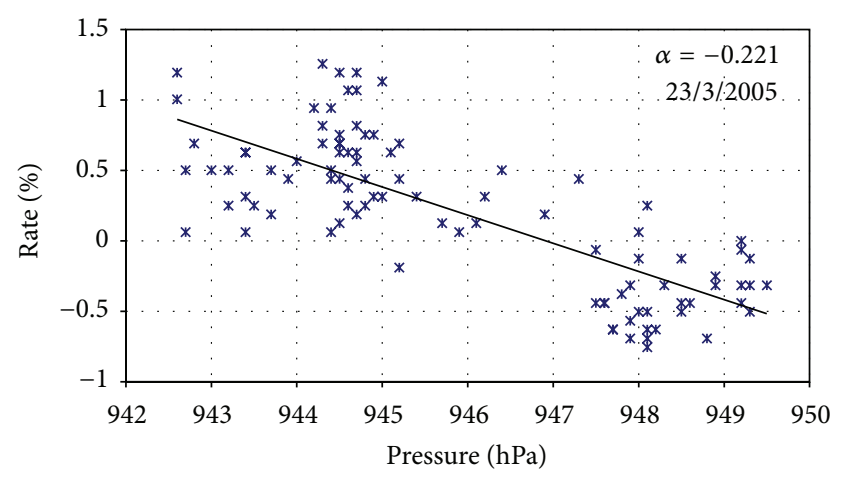

(b)

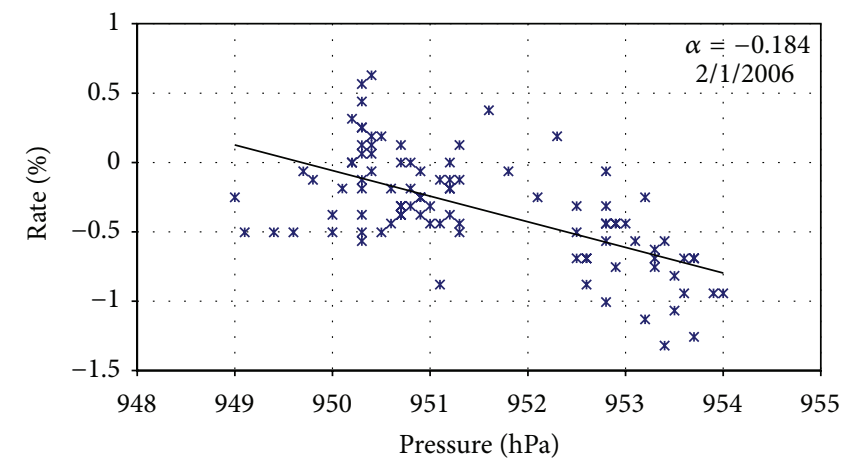

(c)

FIGURE 1: Scatter plot between the pressure and the muon count rate for different days; the straight line is the best fit line in which the slope is the barometric coefficient found in (2).

the period of measurements. We have linearly interpolated up to 5 consecutive missing data points for a certain day. Larger gaps were not considered, and the days that have such large amounts of missing data are excluded from the analysis. Data for barometric coefficient calculation is selected at time periods when there were no large solar flares, magnetic storms, or Forbush decreases.

The intensity of the secondary cosmic ray varies with the change in the atmospheric pressure as $[15,21]$

$$
\frac{d I}{I}=\alpha d P
$$

where $I$ is the cosmic ray rate at pressure $P$ and $\alpha$ is the barometric coefficient. For the $i$ th hour reading of intensity $I_{i}$ and pressure $P_{i}$, the relationship can be written as

$$
\frac{I_{i}-I_{0}}{I_{0}}=\alpha\left(P_{i}-P_{0}\right) .
$$

$I_{0}$ and $P_{0}$ are the mean values of intensity and pressure for the time period being considered. A least squares fit between the hourly values of muon intensities and atmospheric pressure for each day was performed, and the daily value of $\alpha$ was obtained (Figure 1). To understand the distribution of the barometric coefficient by month, daily $\alpha$ values were binned into 12 categories. To investigate the seasonal variations, data were divided into four seasonal groups. Annual variations were studied by taking the twelve-month mean of daily $\alpha$ values.

\section{Results and Discussion}

3.1. The Distribution. Figure 2 indicates the frequency distribution of the calculated daily values of $\alpha$ for 2717 days. The skewness and the kurtosis for this distribution were -0.632 and 2.12 , respectively. $\alpha$ ranges between $-0.61 \% / \mathrm{hPa}$ and $-0.001 \% / \mathrm{hPa}$ with a mean value of $-0.18 \pm 0.001 \% / \mathrm{hPa}$. This wide range of variability can be attributed to several factors. For example, local, regional, and large scale changes in the atmospheric conditions can severely change the atmospheric mass above the detector. Moreover, some extraterrestrial factors affecting either the muon observations or the atmospheric pressure cannot be excluded [22]. It is obvious that the broad range of barometric coefficients supports the idea that the determination of $\alpha$ over longer periods is of great importance for any cosmic ray detecting experiment and modulation study [16, 21, 23-25].

Figure 3 demonstrates the diversity of using different values of $\alpha$ to correct the effect of the atmospheric pressure on the muon rate. It presents data collected over a period of one month. The three $\alpha$ values used were the eleven years value $\left(\alpha_{11}\right)$, the value obtained for that month $\left(\alpha_{\text {Jan }}\right)$, and twice the eleven years value $\left(\alpha_{0.33}\right)$. It can be seen that the phases of the corrected data obtained from the three coefficients agreed for all the times. However, differences in the observed rate of approximately $1.7 \%$ and $2.4 \%$ between $\alpha_{0.33}-\alpha_{11}$ and $\alpha_{0.33}-\alpha_{\text {Jan }}$, respectively, were found during some times. In some situations, above one percent is considered 


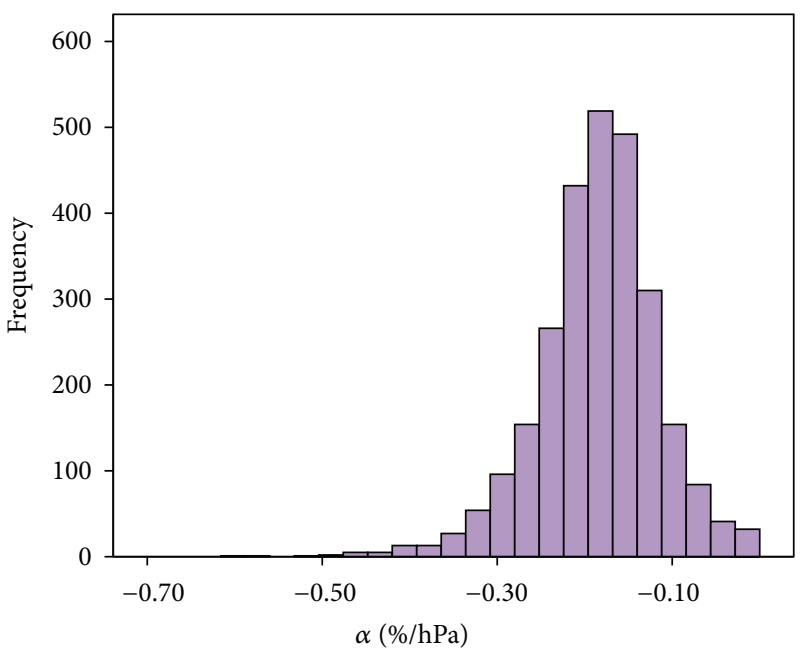

FIGURE 2: The frequency distribution of the calculated daily values of the barometric coefficients, $\alpha$, for 2717 days.

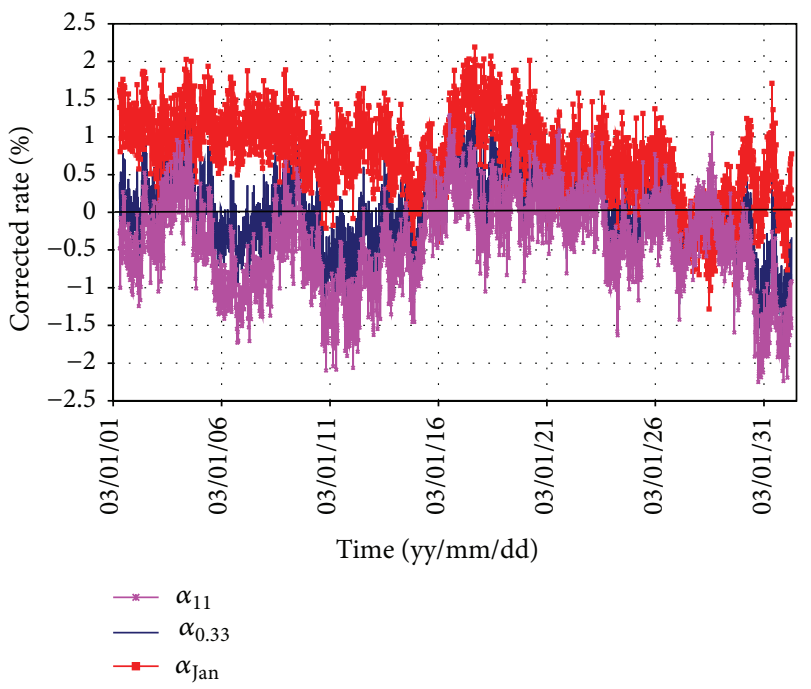

FIGURE 3: The effect of using different values of $\alpha$ to correct the effect of the atmospheric pressure on the detected cosmic ray muon for the whole month of January 2003. The $\alpha$ values used were $\alpha_{11}$ (eleven years average value), $\alpha_{\text {Jan }}$ (obtained for this specific month), and $\alpha_{0.33}$.

to be a large change, particularly in studying certain cosmic ray variations such as the diurnal variations and Forbush decreases $[25,26]$. The above results evidently indicated that one should carefully choose the suitable pressure correction prior to any cosmic ray modulation studies [27]. Based on the above results, we suggest that the $\alpha_{11}$ is the most suitable value for any pressure correction in Riyadh.

3.2. Monthly Variations. The monthly variations of $\alpha$ during the study period are presented in Figure 4 . The barometric coefficient exhibits a slight increase of approximately $4 \%$ from March until May. Then, it increases dramatically to reach its maximum in September when it then starts to decrease again. The maximum increase was approximately $30 \%$ from the monthly mean value. It is noticeable that the mean monthly $\alpha$ variation follows the mean monthly variation of air temperature in some months but not all of them.
November and December exhibited a deviation (from the mean value of eleven years, $\alpha_{11}$ ) of less than $2 \%$. February, April, and August deviated by approximately 10\%. In March, May, and July, the deviations were $-6.374 \%,-8.477 \%$, and $5.289 \%$, respectively. Whereas June exhibited the minimum deviation of $-0.072 \%$, September exhibited a deviation of approximately $15 \%$.

Cosmic ray data from Adelaide muon detector for the period 2003-2012 were used for comparison purposes [4]. Least squares fit between the monthly cosmic rays intensities and atmospheric pressure was performed to obtain the barometric coefficients. Monthly variations of $\alpha$ from this site are presented in Figure 5. It is apparent that, although the Adelaide detector has almost the same technical specifications as our detector, its monthly variation was opposite to ours. The barometric coefficient reaches its maximum value in winter (southern hemisphere) and its minimum value in summer. 


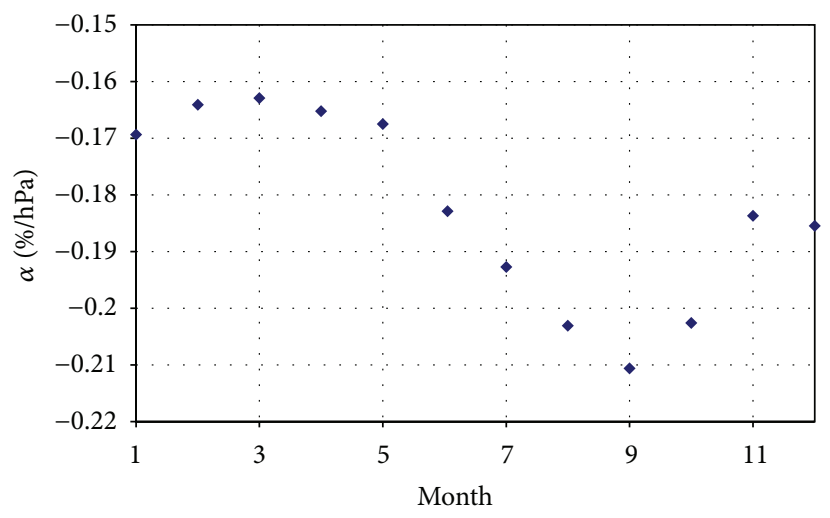

FIGURE 4 : The monthly variations of $\alpha[\% / \mathrm{hPa}]$ over Riyadh for the whole study period.

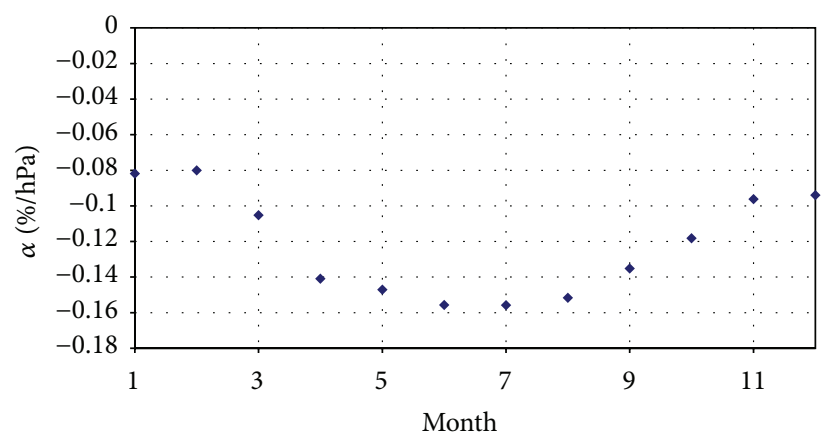

FIgURE 5: It is the same as Figure 4 but for Adelaide muon detector.

These monthly differences between two stations having the same detection system cannot be solely contributed to the temperature variations. This fact indicates that other factors, such as other meteorological and atmospheric causes, need to be considered.

3.3. Seasonal Variations. Table 1 presents the mean, maximum, and minimum values of $\alpha$ for the four seasons. In addition, the mean, minimum, and maximum calculated deviations of $\alpha$ from the $\alpha_{11}$ are presented.

Inspection of the data indicates that the lowest mean value of $\alpha$ was in winter followed by summer. Both fall and spring have nearly the same mean values, for which their deviations from the $\alpha_{11}$ were the minimum. The maximum obtained value was in fall $(-0.605)$ followed by spring $(-0.559)$, while the minimum $\alpha$ was in summer and spring. It is clear that the deviations of these values from the $\alpha_{11}$ were extremely high.

Figure 6 presents the seasonal (interannual) variations in $\alpha$. Apart from an unexplained decrease in 2004, the general trend during this period for all the seasons is a gradual decrease in $\alpha$ from 2002, reaching the minimum in 2008. Then, it starts to increase at different levels from one season to another.

It is beyond the scope of the present study to investigate the mechanisms responsible for this variability because detailed information and different types of data sources are needed.

3.4. Annual Variations. Figure 7(a) shows the twelve-month running mean of the $\alpha$ (annual values). The main observed trend during this period is a gradual decrease in the barometric coefficient that started in $2002(-0.22)$ and stayed around the minimum in $2009(-0.13)$. Then, it starts to increase again.

The variable tendency of the annual $\alpha$ values can be investigated in association with the solar activity as noted by several others (e.g., [26], and others). In this regard, the mean monthly sunspot numbers (SSN) were used as an indicator for the solar activity. These data were obtained from Solar Geophysical Data (SGD) of the National Oceanic and Atmospheric Administration (NOAA) and the National Geophysical Data Center (NGDC) of the USA. The relationship between the two parameters is displayed in Figure 7(a). It demonstrates that there is a close association between the two parameters in which $\alpha$ is in inverse relationship with the SSN. Figure 7(b) shows the same relationship between the annual variations of $\alpha$ and the SSN, but for Adelaide muon detector. Nevertheless, previous studies [28] showed that there is a positive relationship between the barometric coefficients obtained from neutron monitors and the SSN. The agreement between the two muon detectors found in this 
TABLE 1: Summarization of the mean, maximum, and minimum values of $\alpha$ for the four seasons. The last three columns are mean, minimum, and maximum deviations of $\alpha$ from the $\alpha_{11}$.

\begin{tabular}{|c|c|c|c|c|c|c|}
\hline Season & $\begin{array}{c}\text { Mean } \\
{[\% / \mathrm{hPa}]}\end{array}$ & $\begin{array}{c}\text { Max. } \\
{[\% / \mathrm{hPa}]}\end{array}$ & $\begin{array}{c}\text { Min. } \\
{[\% / \mathrm{hPa}]}\end{array}$ & $\begin{array}{c}\text { Mean dev. } \\
\%\end{array}$ & $\begin{array}{c}\text { Max. dev. } \\
\%\end{array}$ & $\begin{array}{c}\text { Min. dev. } \\
\%\end{array}$ \\
\hline Fall & -0.1841 & -0.605 & -0.008 & 0.636 & 230.601 & -95.628 \\
\hline Spring & -0.1869 & -0.559 & -0.003 & 2.140 & 205.464 & -98.360 \\
\hline Summer & -0.1651 & -0.517 & -0.001 & -9.753 & 182.513 & -99.453 \\
\hline Winter & -0.158 & -0.480 & -0.011 & -13.261 & 162.295 & -93.989 \\
\hline
\end{tabular}

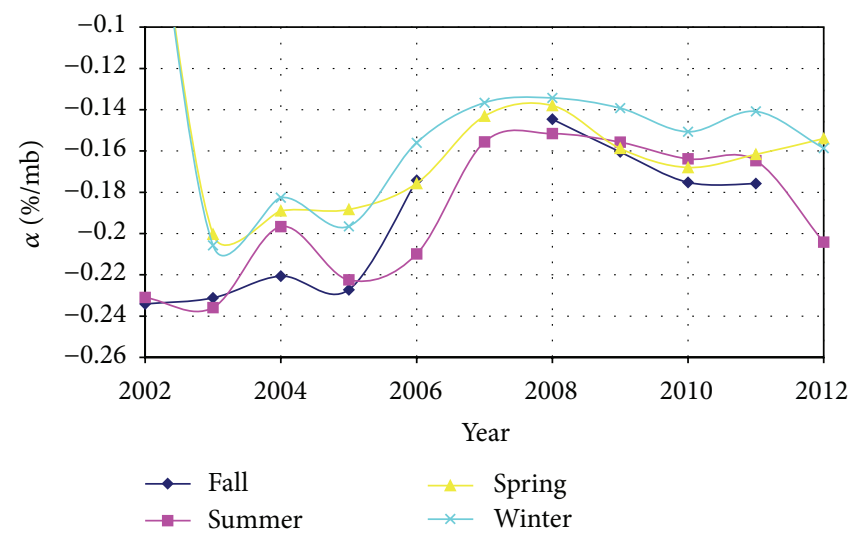

FIgURE 6: Time series of interannual variation of $\alpha[\% / \mathrm{hPa}]$ for the four seasons.

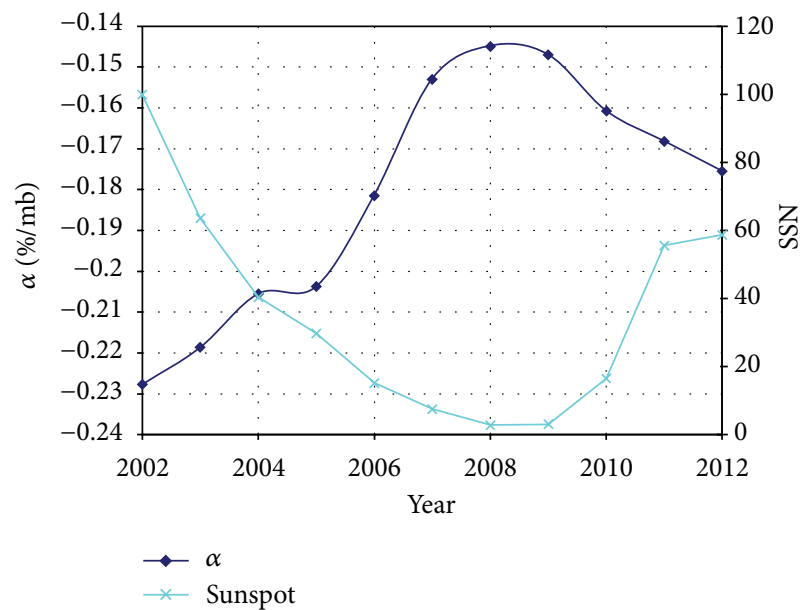

(a)

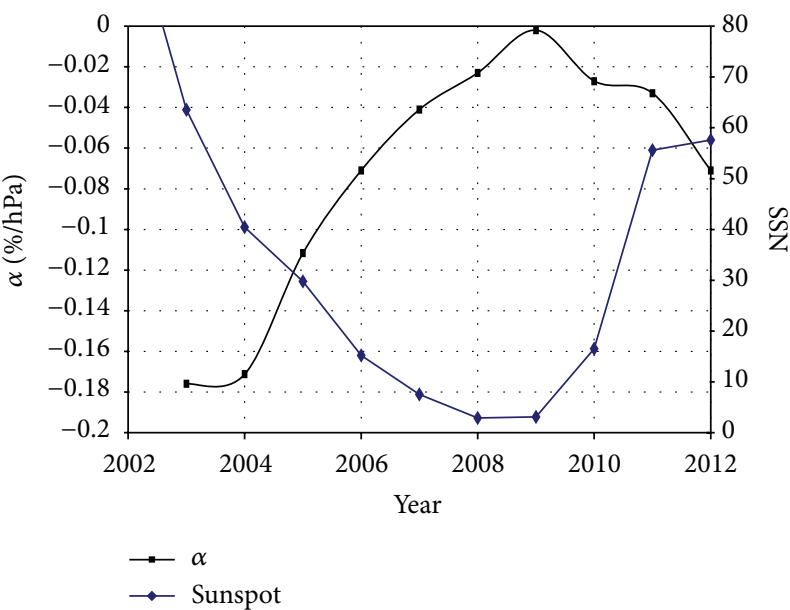

(b)

FIGURE 7: (a) The annual values of the barometric coefficient $\alpha$ for Riyadh and the sunspot number (SSN) for the period 2002 to 2012 . (b) is the same as (a) but for Adelaide muon detector for the period 2003 to 2012.

study (inverse relationship between $\alpha$ and the SSN) may be somehow related to the temperature effect on the cosmic ray muons. This issue is the topic of ongoing research.

\section{Conclusion}

The atmospheric corrections for muon detectors are assuming pressure, height of pion production level, and temperature. This paper provides first step in the atmospheric correction, namely, the correction to the total mass (represented by the atmospheric pressure) above the detector. The barometric coefficient $(\alpha)$ was calculated using regression analysis between atmospheric pressure and cosmic ray data obtained from KACST muon detector for the period 20022012. It was found that that barometric coefficients exhibit a wide range of values. This result proves that the appropriate barometric coefficient needs to be determined by long-term monitoring of the atmospheric pressure and cosmic ray 
flux. The variation of $\alpha$ over different time scale was investigated. The results revealed a seasonal cycle of $\alpha$, which, to some extent, follows the mean monthly variation of air temperature. Data from Adelaide muon detector (same as our detector but located in the southern hemisphere) showed that $\alpha$ reached its maximum value in winter and its minimum value in summer. Yet, no clear explanations for this discrepancy between the two sites can be reached.

The barometric coefficient displays considerable variability at the interannual scale. No clear conclusion can be reached; however, the interannual variations in air-mass frequency over the study region may be a possible cause. Study of the annual variations of $\alpha$ indicated cyclic variation with maximums between 2008 and 2009 and minimums between 2002 and 2003. This variable tendency of $\alpha$ is found anticorrelated with solar activity, represented by the sunspot number. This finding was in agreement with data obtained from the Adelaide muon detector.

The effect of atmospheric temperatures and the height of the pion production level on the cosmic ray muons is the subject of ongoing research activity.

\section{Conflict of Interests}

There is no conflict of interests related to this paper

\section{Acknowledgments}

The authors would like to thank King Abdulaziz City for Science and Technology (KACST) for supporting this work. The High Energy Astrophysics group at the University of Adelaide Australia is highly acknowledged for making the muon detector data available. They also thank the reviewers for their valuable comments and suggestions.

\section{References}

[1] M. Bercovitch, "Atmospheric effects on cosmic ray monitors," in Proceedings of the International Conference on on Cosmic Rays, pp. 269-344, Calgary, Canada, 1967.

[2] H. S. Ahluwalia, "Galactic cosmic ray intensity variations at a high latitude sea level site 1937-1994," Journal of Geophysical Research, vol. 102, no. A11, pp. 24229-24236, 1997.

[3] L. I. Dorman, Cosmic Rays, Variations and Space Exploration, North-Holland, Amsterdam, The Netherlands, 2004.

[4] M. Berkova, R. Clay, E. Eroshenko, and V. Yanke, "Atmospheric Variations as observed by Adelaide and Buckland Park muon telescopes," in Proceedings of the 33rd International Conference on Cosmic Ray, pp. 230-234, Rio De Janero, Brazil, 2013.

[5] A. V. Belov and L. I. Dorman, "Dependence of cosmic ray barometer effect on primary variation spectrum," in Proceedings of the 16th International Conference on Cosmic Rays, vol. 4, pp. 310-314, Kyoto, Japan, 1979.

[6] C. V. Harman and C. J. Hatton, "Contributions to the counting rate and the temperature dependence of neutron monitors," Canadian Journal of Physics, vol. 46, no. 10, pp. S1052-S1056, 1968.

[7] M. A. Forman, "Neutron monitor mass absorption coefficients at Chicago and climax during solar cycle 19 (1954-1963),"
Journal of Geophysical Research, vol. 70, no. 11, pp. 2469-2473, 1965.

[8] L. I. Dorman, O. G. Rogava, and L. K. H. Shatashvili, "Planetary distribution of cosmic ray neutron component barometric coefficients during IQSY," Geomagnetism and Aeronomy, vol. 8, no. 1, pp. 166-167, 1968.

[9] D. H. Loughridge and P. F. Gast, "Further investigations of the air mass effect on cosmic-ray intensity," Physical Review, vol. 58, no. 7, pp. 583-585, 1940.

[10] W. K. Griffiths, C. V. Harman, C. J. Hatton, and P. Ryder, "Studies of the barometric coefficients of IGY and NM-64 neutron monitors," in Proceedings of the International Conference on Cosmic Rays, pp. 475-477, London, UK, 1965.

[11] W. K. Griffiths, C. V. Harman, C. J. Hatton, P. L. Marsden, and P. Ryder, "The intensity variations of selected multiplicities in the Leeds NM64 neutron monitor," Canadian Journal of Physics, vol. 46, pp. S1044-S1047, 1968.

[12] T. T. Quang, A. G. Fenton, and K. B. Fenton, "Effect of the muon contribution on the barometric coefficient of neutron monitors," Astronomical Society of Australia, vol. 2, no. 5, 1974.

[13] R. C. López and J. F. Valdés-Galicia, "Variations in cosmic radiation intensity associated with the barometric effect," Geofisica Internacional, vol. 39, no. 1, pp. 135-137, 2000.

[14] M. Kusunose, "Year-to-year variation in the barometer coefficient of cosmic ray neutron monitor located at high latitude," Memoirs of the Faculty of Science Kochi University Series B, vol. 5, pp. 15-20, 1985.

[15] M. Kusunose, N. Ogita, and S. Yoshida, "Examination of the barometric coefficients of neutron monitor data," in Proceedings of the 17th International Cosmic Ray Conference, vol. 10, pp. 281284, Paris, France, 1981.

[16] A. Chilingarian, T. Karapetyan, and B. Mailyan, "Calculation of the barometric coefficients for the particle detectors belonging to the world-wide networks at the start of the 24th Solar Activity cycle," in Proceedings of the 31st International Cosmic Ray Conference, Łodz, Poland, 2009.

[17] A. H. Maghrabi, H. Al Harbi, Z. A. Al-Mostafa, M. N. Kordi, and S. M. Al-Shehri, "The KACST muon detector and its application to cosmic-ray variations studies," Advances in Space Research, vol. 50, no. 6, pp. 700-711, 2012.

[18] A. H. Maghrabi, H. H. Alharbi, A. S. Alghamdi, A. A. Alwaheeb, and M. M. Almuteri, "Cosmic ray detectors for variation studies and outreach programs in Saudi Arabia," in Proceedings of the 33th International Cosmic Ray Conference (ICRC '13), Rio De Janeiro, Brazil, July 2013.

[19] A. H. Maghrabi, A. S. Alghamdi, R. Alotaibi, M. Almutari, and M. S. Garawi, "On the calibration of a single channel cosmic ray particle detector," in High Energy, Optical, and Infrared Detectors for Astronomy VI, vol. 9154 of Proceedings of SPIE, 91542K, July 2014.

[20] A. Alghamdi, A. H. Maghrabi, and M. M. Almutari, "Designing and constructing of a two scintillator crystal rotatable telescope for muon flux variation studies," in High Energy, Optical, and Infrared Detectors for Astronomy VI, vol. 9154 of Proceedings of SPIE, Montreal, Canada, July 2014.

[21] R. R. S. De Mendonça, J.-P. Raulin, F. C. P. Bertoni, E. Echer, V. S. Makhmutov, and G. Fernandez, "Long-term and transient time variation of cosmic ray fluxes detected in Argentina by CARPET cosmic ray detector," Journal of Atmospheric and Solar-Terrestrial Physics, vol. 73, no. 11-12, pp. 1410-1416, 2011.

[22] S. Kawasaki, "On the anomalous barometer coefficient of cosmic-ray neutron monitor at Mt. Norikura," Scientific Papers 
of the Institute of Physical and Chemical Research, vol. 66, pp. 25-32, 1972.

[23] K. Kudela and M. Storini, "Cosmic ray variability and geomagnetic activity: a statistical study," Journal of Atmospheric and Solar-Terrestrial Physics, vol. 67, no. 10, pp. 907-912, 2005.

[24] K. Kudela, K. A. Firoz, R. Langer, and V. Kollár, "On diurnal variation of cosmic rays: statistical study of neutron monitor data including Lomnicky stit," in Proceedings of the 21st European Cosmic Ray Symposium (ECRS '08), pp. 374-378, Košice, Slovakia, 2008.

[25] S. Kumar, R. Agarwal, R. Mishra, and S. K. Dubey, "Daily variation in cosmic ray intensity on different geomagnetic conditions," International Journal of Modern Physics D, vol. 11, no. 8, pp. 1243-1253, 2002.

[26] M. Kusunose and N. Ogita, "On the solar cycle variation in the barometer coefficients of high latitude neutron monitors," in Proceedings of the 19th International Cosmic Ray Conference, vol. 5, pp. 305-308, La Jolla, Calif, USA, 1985.

[27] S. M. Lapointe and D. C. Rose, "A statistical analysis of the barometer coefficients cosmic-ray intensities," Canadian Journal of Physics, vol. 40, pp. 687-697, 1962.

[28] S. Kawasaki, "Free air pressure reduced from radiosonde data for the correction of cosmic ray barometer effect," in Proceedings of the 16th International Cosmic Ray Conference, vol. 4, pp. 263265, Kyoto, Japan, 1979. 

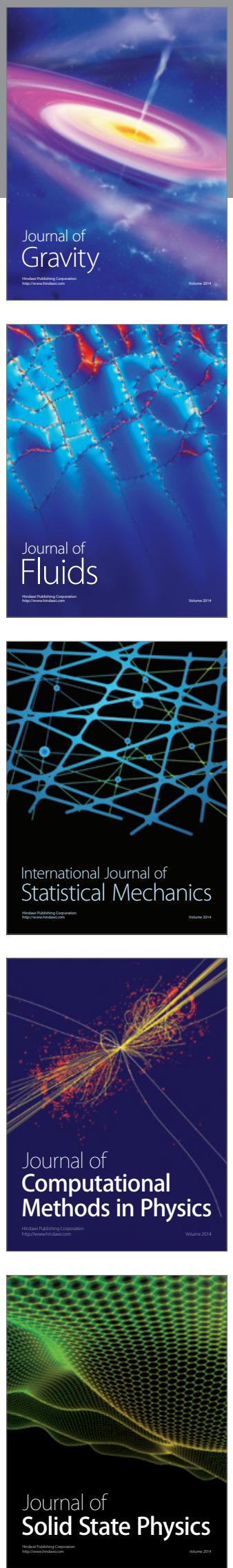

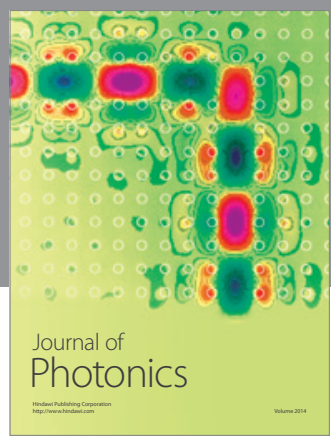

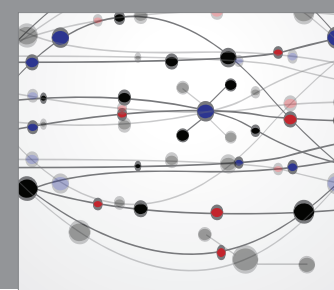

The Scientific World Journal

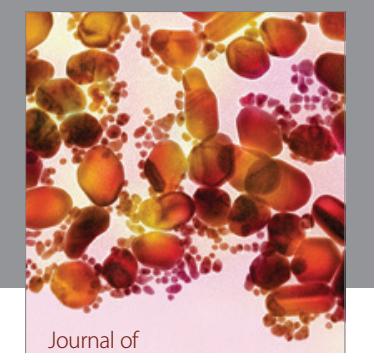

Soft Matter
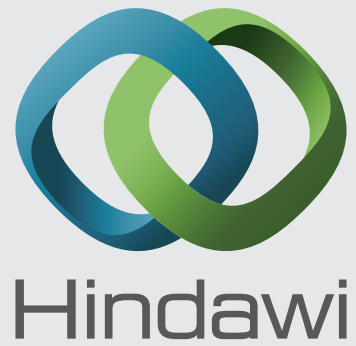

Submit your manuscripts at

http://www.hindawi.com
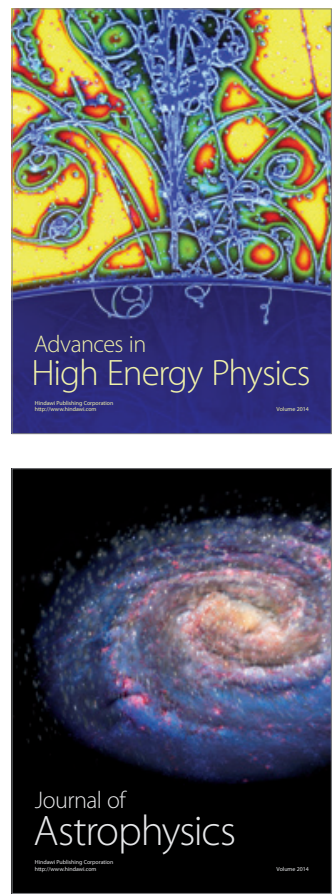
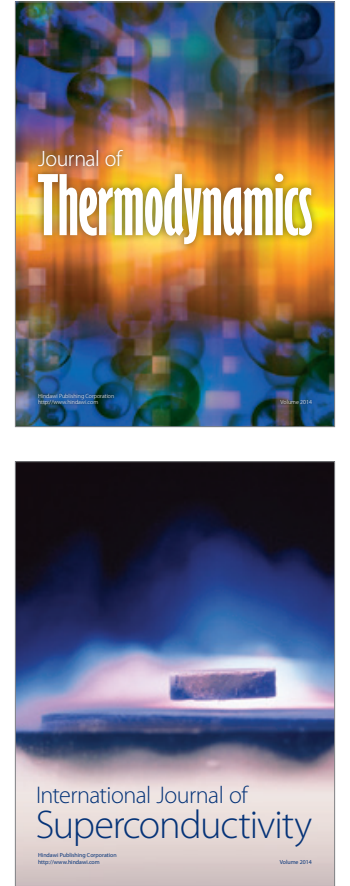
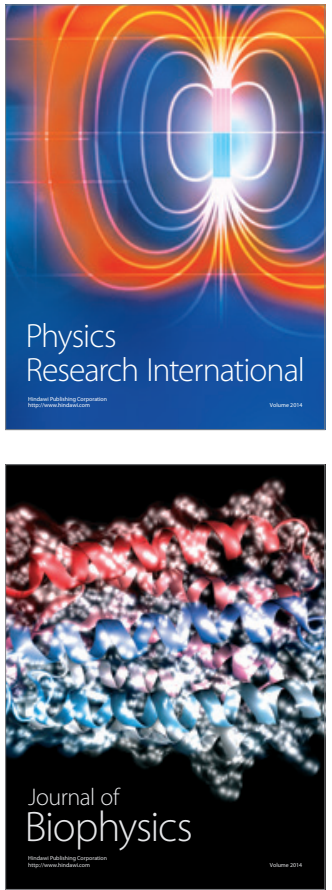
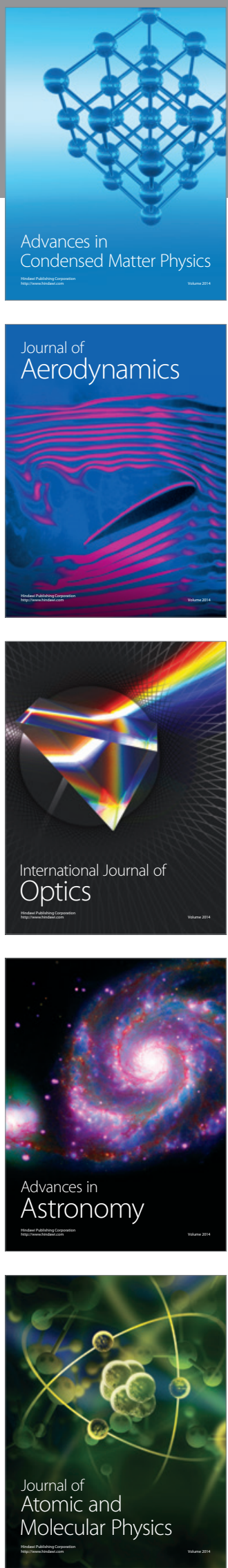